\title{
Patient drift and response-adaptive randomisation: impact and solutions
}

\author{
Sofia S Villar", James Wason, Jack Bowden \\ From 3rd International Clinical Trials Methodology Conference \\ Glasgow, UK. 16-17 November 2015
}

There is a considerable interest in using response-adaptive randomisation in clinical trials. Several reasons motivate this. First, they improve individual patient response in clinical trials by increasing the allocation to a best performing treatment (if it exists). Skewing its allocation probability as data accumulates. Second, in multi-armed trials, by protecting the allocation to the control treatment, one can identify trial designs that score highly in both statistical power and patient benefit. Moreover, in this context, by testing many promising treatments simultaneously, multiarm trials increase the probability of finding a successful new treatment, speeding up the process of doing so. Despite this, response-adaptive designs have seldom been used in practice. One of the major criticisms of responseadaptive randomisation is the potential for type-one error inflation due to "patient drift". Patient drift can include changes in patients characteristics or the effectiveness of treatments over time. There have been few papers quantifying the extent to which this phenomena actually affects the operating characteristics and how to best correct for it.

In this talk we present work addressing both questions for novel adaptive randomisation methods. We consider several scenarios and allocation rules to assess how the type and magnitude of the drift affects the type-one error rate for these designs. We further suggest and assess statitiscal procedures that preserve type one error in the presence of unknown patient drift in both a twoarm and a multi-arm trial setting.

Published: 16 November 2015

doi:10.1186/1745-6215-16-S2-P232

Cite this article as: Villar et al:: Patient drift and response-adaptive randomisation: impact and solutions. Trials 2015 16(Suppl 2):P232.

MRC Biostatistics Unit, Cambridge, UK

(c) 2015 Villar et al. This is an Open Access article distributed under the terms of the Creative Commons Attribution License (http:// creativecommons.org/licenses/by/4.0), which permits unrestricted use, distribution, and reproduction in any medium, provided the original work is properly cited. The Creative Commons Public Domain Dedication waiver (http://creativecommons.org/publicdomain/ zero/1.0/) applies to the data made available in this article, unless otherwise stated.

Submit your next manuscript to BioMed Central and take full advantage of:

- Convenient online submission

- Thorough peer review

- No space constraints or color figure charges

- Immediate publication on acceptance

- Inclusion in PubMed, CAS, Scopus and Google Scholar

- Research which is freely available for redistribution 